\title{
Mucosal gastric calcinosis in a hypocalcaemic patient
}

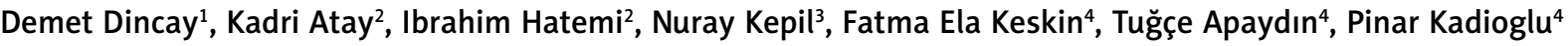 \\ ${ }^{1}$ Department of Internal Medicine, Cerrahpaşa Medical Faculty, Istanbul University, Istanbul, Turkey \\ 2Department of Gastroenterology, Cerrahpasa Medical Faculty, Istanbul University, Istanbul, Turkey \\ ${ }^{3}$ Department of Pathology, Cerrahpasa Medical Faculty, Istanbul University, Istanbul, Turkey \\ ${ }^{4}$ Department of Internal Medicine Endocrinology, Cerrahpaşa Medical Faculty, Istanbul University, Istanbul, Turkey
}

Gastroenterology Rev 2017; 12 (1): 70-71

DOI: $10.5114 / p g .2016 .61885$

Address for correspondence: Dr Kadri Atay, Department of Gastroenterology, Cerrahpasa Medical Faculty, Istanbul University, 34000 Istanbul, Turkey, phone: +90 2124143000, e-mail: dr_kadrii@yahoo.com

Metastatic calcification is defined as the deposition of calcium salt in normal tissue due to an abnormal serum biochemical environment such as hypercalcaemia or hyperphosphataemia. The most common causes of metastatic calcifications are chronic renal failure, hyperparathyroidism, and hypercalcaemia related to malignancy [1]. Gastric mucosal calcification is an example of metastatic calcification; it was reported mostly in chronic renal failure [2]. We report herein a case of gastric calcinosis in a patient who has hypoparathyroidism.

Our case is a 21-year-old male who has type 1 diabetes and has had idiopathic hypoparathyroidism since he was 5 years old. He was admitted to our hospital with leg and arm spasms. In his medical history the patient had deep hypocalcaemia and hyperphosphataemia due to idiopathic hypoparathyroidism. He also had type 1 diabetes that was uncontrolled, with high levels of glycated haemoglobin $\left(\mathrm{HbA}_{1 \mathrm{c}}\right)$. He was using intensive insulin therapy, sevelamer, anti-phosphate, sucralfate, and calcium supplements. In his physical examination there were Chvostek and Trousseau signs. His blood chemistry was as follows: serum calcium: $6.01 \mathrm{mg} / \mathrm{dl}$ (8.4-10.2 mg/dl), phosphate: $7.7 \mathrm{mg} / \mathrm{dl}$ (2.5-4.5 mg/ $\mathrm{dl}), \mathrm{Ca} \times \mathrm{P}: 46.35 \mathrm{mg}^{2} / \mathrm{dl}^{2}$, albumin: $4 \mathrm{~g} / \mathrm{l}(3.5-5.2 \mathrm{~g} / \mathrm{l})$, potassium: $4.13 \mathrm{mg} / \mathrm{dl}(3.5-5.1 \mathrm{mg} / \mathrm{dl})$, C-reactive protein: $0.36 \mathrm{mg} / \mathrm{dl}(<5 \mathrm{mg} / \mathrm{dl})$, erythrocyte sedimentation rate per hour: $11 \mathrm{~mm}$ (0-20 $\mathrm{mm})$. We planned upper gastrointestinal endoscopy to evaluate iron deficiency anaemia to rule out atrophic gastritis or celiac disease. During the endoscopic procedure multiple biopsies were taken from antrum and corpus of the stomach and from the duodenum. In the histopathological examination there was no sign of atrophic gastritis or villous atrophy, but mucosal calcinosis was reported (Figures $1 \mathrm{~A}-\mathrm{C}$ ).

According to our literature search, mucosal calcinosis has not been reported previously in hypoparathyroidism. On the other hand, basal ganglia calcification, which is another type of metastatic calcification, also known as Fahr's syndrome, is a well-known finding in hypoparathyroidism. We also found this type of basal ganglia and cerebral cortex calcification in our case by cranial magnetic resonance imaging. The pathogenesis of metastatic calcification is not clear [3]. An increase in calcium $\times$ phosphate product or cellular alkalinity may cause metastatic calcifications. Sucralfate therapy was also reported previously as an aetiological factor for mucosal calcification, but the relation was not confirmed by other studies [4]. In our opinion there is no clinical significance of gastric mucosal calcification in this case

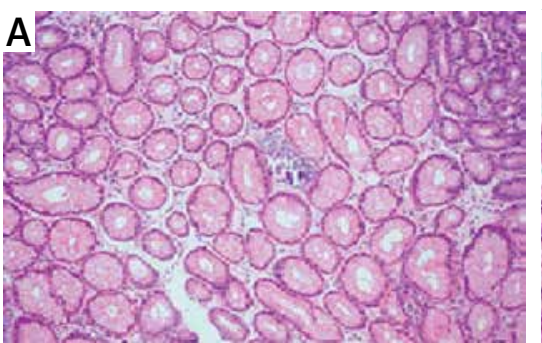

Figure 1 A-C. Mucosal calcinosis
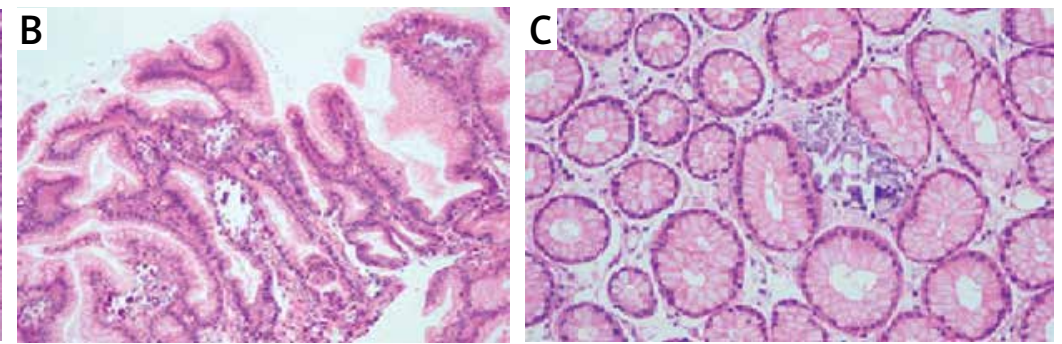
since he was asymptomatic and there was no ulcer or erosion at his endoscopy.

In conclusion, this is the first report of mucosal gastric calcinosis in a hypoparathyroid patient accompanied by cerebral calcification, which may be caused by hyperphosphataemia.

\section{Conflict of interest}

The authors declare no conflict of interest.

\section{References}

1. Coates T, Kirkland GS, Dymock RB, et al. Cutaneous necrosis from calcific uremic arteriolopathy. Am J Kidney Dis 1998; 32: 384-91.

2. Gorospe M, Fadare O. Gastric mucosal calcinosis: clinicopathologic considerations. Adv Anat Pathol 2007; 14: 224-8.

3. Goswami R, Sharma R, Sreenivas V, et al. Prevalence and progression of basal ganglia calcification and its pathogenic mechanism in patients with idiopathic hypoparathyroidism. Clin Endocrinol (Oxf) 2012; 77: 200-6.

4. Greenson JK, Trinidad SB, Pfeil SA, et al. Gastric mucosal calcinosis. Calcified aluminum phosphate deposits secondary to aluminum-containing antacids or sucralfate therapy in organ transplant patients. Am J Surg Pathol 1993; 17: 45-50.

Received: 9.02.2016

Accepted: 5.04.2016 